\title{
Recent advances in transthyretin amyloidosis therapy
}

\author{
Mitsuharu Ueda ${ }^{1}$ and Yukio Ando ${ }^{2^{*}}$
}

\begin{abstract}
Mutant (MT) forms of transthyretin (TTR) cause the most common type of autosomal-dominant hereditary systemic amyloidosis - familial amyloidotic polyneuropathy (FAP). Until 20 years ago, FAP was thought to be an endemic disease, but FAP is known to occur worldwide. To date, more than 130 mutations in the TTR gene have been reported. Genotype-phenotype correlations are seen in FAP, and some variation in clinical presentation is often observed in individual kindreds with the same mutation and even among family members. Of the pathogenic TTR mutations, Val30Met was the first to be identified and is the most frequent known mutation found throughout the world. Studies of patients with FAP amyloidogenic TTR (ATTR) Val30Met documented sensorimotor polyneuropathy, autonomic dysfunction, heart and kidney failure, gastrointestinal tract (Gl) disorders, and other symptoms leading to death, usually within 10 years of the onset of disease. Diagnosis is sometimes delayed, especially in patients without a clear family history and typical clinical manifestations, since diagnosis requires various studies and techniques such as histopathology, genetic testing, and mass spectrometry. For treatment of FAP, liver transplantation (LT) reportedly halts the progression of clinical manifestations. Exchange of an FAP patient's diseased liver with a healthy liver causes MT TTR in the body to be replaced by wild-type (WT) TTR. Although clinical evaluations indicated that progression of other clinical symptoms such as peripheral neuropathy, GI symptoms, and renal involvement usually halted after LT in FAP ATTR Val30Met patients, recent studies suggested that LT failed to prevent progression of cardiac amyloidosis in FAP ATTR Val30Met patients after LT, with this failure reportedly being due to continued formation of amyloid that derived mainly from WT TTR secreted from the transplanted non-mutant liver graft. In recent years, many therapeutic strategies have been proposed, and several ongoing therapeutic trials involve, for example, stabilizers of TTR tetramers (tafamidis and diflunisal) and gene therapies to suppress TTR expression (antisense methods and use of small interfering RNAs). These novel therapies may prove to prevent progression of FAP.
\end{abstract}

Keywords: Transthyretin, Amyloidosis, Familial amyloidotic polyneuropathy, Senile systemic amyloidosis, Immunotherapy, Gene therapy

\section{Introduction}

Mutant (MT) forms of transthyretin (TTR) cause the most common type of autosomal-dominant hereditary systemic amyloidosis-familial amyloidotic polyneuropathy (FAP) [1-3]. In recent years, many therapeutic strategies have been proposed, and several therapeutic trials for FAP are ongoing $[4,5]$. Here, we review clinical presentation, pathogenesis, diagnostic purpose, and recent advances in the treatment of this disease.

\footnotetext{
* Correspondence: andoy709@kumamoto-u.ac.jp

${ }^{2}$ Department of Neurology, Graduate School of Medical Sciences, Kumamoto University, 1-1-1 Honjo, 860-0811 Kumamoto, Japan

Full list of author information is available at the end of the article
}

\section{Amyloidosis and TTR}

Amyloidosis is a protein conformational disorder characterized by extracellular accumulation of amyloid fibrils derived from various proteins [6-8]. Thus far, 30 distinct protein precursors of amyloid fibrils have been identified as causing different kinds of amyloidosis [9-12]. Depending on the type of amyloidosis, various factors can be responsible for protein aggregation.

TTR, a major amyloidogenic protein, is mainly synthesized in the liver [13] but also in the choroid plexuses of the brain [14], retinal pigment epithelial (RPE) cells of the eye [15], and $\alpha$-cells of pancreatic islets [16]. TTR forms a homotetramer that has a dimer-of-dimers configuration in the bloodstream and that acts as a plasma transport 
protein for thyroid hormone and retinol-binding protein with vitamin A [17]. The plasma TTR concentration is reduced in conditions involving inflammation and protein malnutrition [18]. TTR causes two kinds of amyloidotic diseases. One is a hereditary systemic amyloidosis, FAP, which is induced by MT TTR [1-3]. The other type is senile systemic amyloidosis (SSA), which is an aging-related sporadic systemic amyloidosis that is induced by wild-type (WT) TTR [19,20]. Destabilization of TTR tetramers is widely believed to be a critical step in TTR amyloid formation (Figure 1) [21].

\section{FAP}

Until 20 years ago, FAP was believed to be a disease that was restricted to an endemic presence in those specific areas. However, progress in biochemical and molecular genetic analyses resulted in an understanding that this disease now occurs worldwide. To date, more than 130 mutations in the TTR gene have been reported [2,22]. Although 15 TTR mutations are nonamyloidogenic, other TTR mutations induce systemic amyloidosis, which can be classified into several phenotypes including peripheral neuropathy dominant type, commonly called FAP; cardiomyopathy dominant type, also known as familial amyloidotic cardiomyopathy; vitreous opacity dominant type, which is thought to be derived mainly from TTR synthesized from RPE cells; and leptomeningeal amyloidosis dominant type, which is believed to be derived mainly from the choroid plexuses of the brain and causes central nervous symptoms. Hereditary TTR amyloidosis manifests genotype-phenotype correlations [2,23,24], and some variation in clinical presentation is often observed in individual kindreds with the same mutation and even among family members. Of the pathogenic TTR mutations, Val30Met was the first to be identified and is the best known mutation found throughout the world, although the reason for this distribution is not known.

In Japan, Araki et al. first reported a group of patients with FAP ATTR Val30Met in Kumamoto [22]. Sensorimotor polyneuropathy, autonomic dysfunction, heart and kidney failure, gastrointestinal (GI) tract disorders, and other symptoms (Figure 2) that led to death, usually within 10 years of the onset of disease, have been documented in patients with FAP ATTR Val30Met [1]. In addition to the two endemic foci that were identified in Japan, many other FAP kindreds with TTR Val30Met and other mutations were found in Japan (Figure 3). That phenotypic differences exist among patients with the same Val30Met mutation and depend on geographic origin is well known [3,25-27]. Families originating from Portugal and two endemic areas in Japan (Arao city in Kumamoto Prefecture and Ogawa village in Nagano Prefecture) usually have early-onset and high-penetrance FAP, whereas other Japanese kindreds and Swedish families evidence late-onset and low-penetrance FAP [3,25-27]. Recent studies reported that certain Swedish patients with late-onset FAP ATTR Val30Met have amyloid deposits containing truncated TTR [28-31], which is usually found in SSA, a sporadic form of TTR amyloidosis [28,32]. Morphological ultrastructural studies showed that amyloid fibrils in those cases were tightly packed, haphazardly arranged, and fairly short compared with fibrils from other FAP ATTR Val30Met patients, usually with early-onset disease, who did not have truncated TTR in amyloid deposits [28]. The specific functional and pathological roles of truncated TTR remain to be determined, however.

\section{SSA}

SSA, in which WT TTR forms amyloid deposits in various tissues, is an age-related nonhereditary systemic amyloidosis 


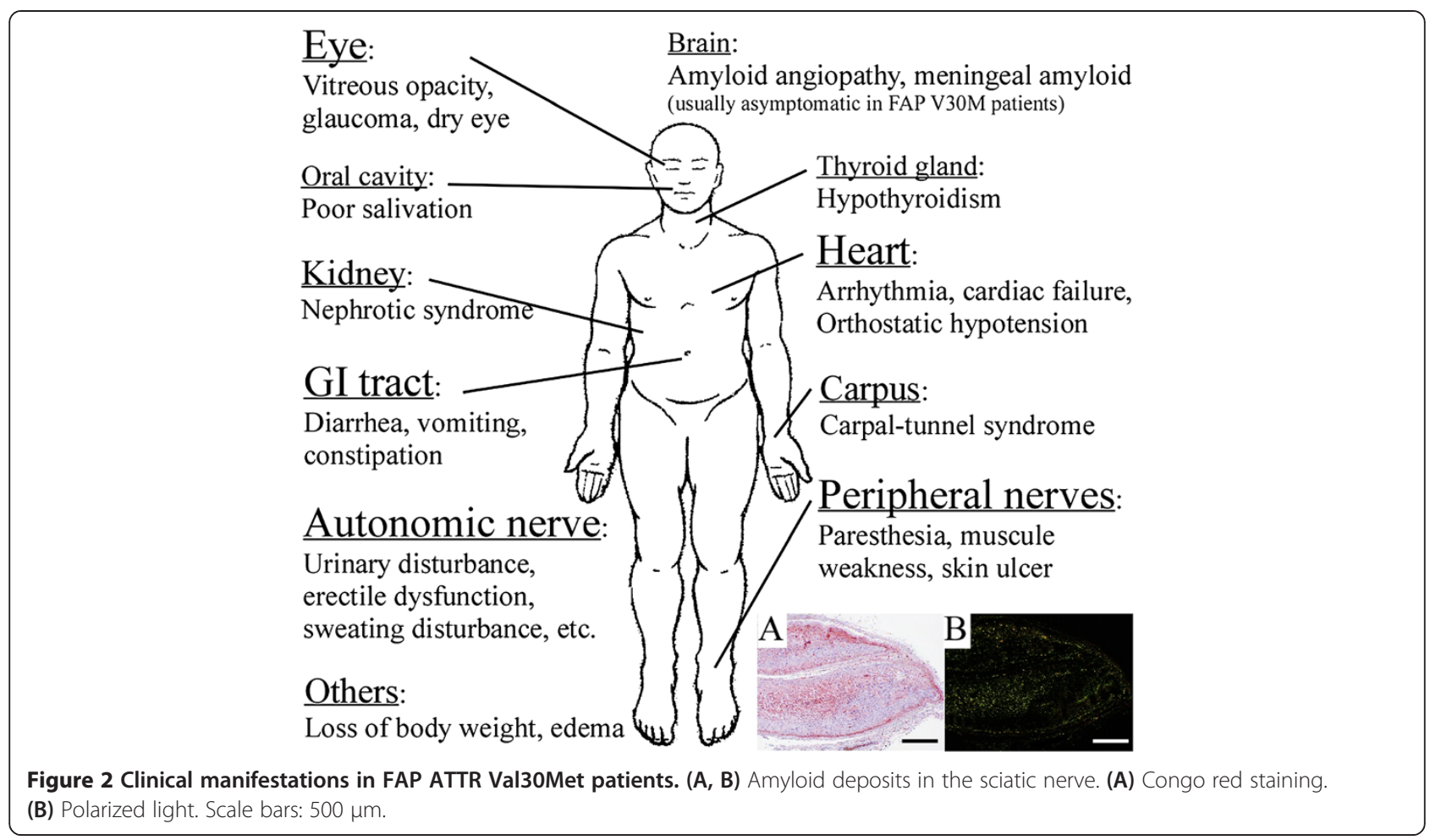

and affects mainly cardiac functions in elderly people [19,20,33-35]. Postmortem studies demonstrated that the prevalence of SSA was $12-25 \%$ in patients older than 80 years $[19,20]$. Furthermore, recent studies determined that WT TTR amyloid may also cause several other disorders and conditions [12], such as radiculomyelopathy [36], tongue necrosis [37], hematuria [38], nodular amyloid deposits in the lung [39], and frequent amyloid deposition in ligaments and tendons such as carpal tunnel and spinal ligaments $[40,41]$, to a degree not previously known. In

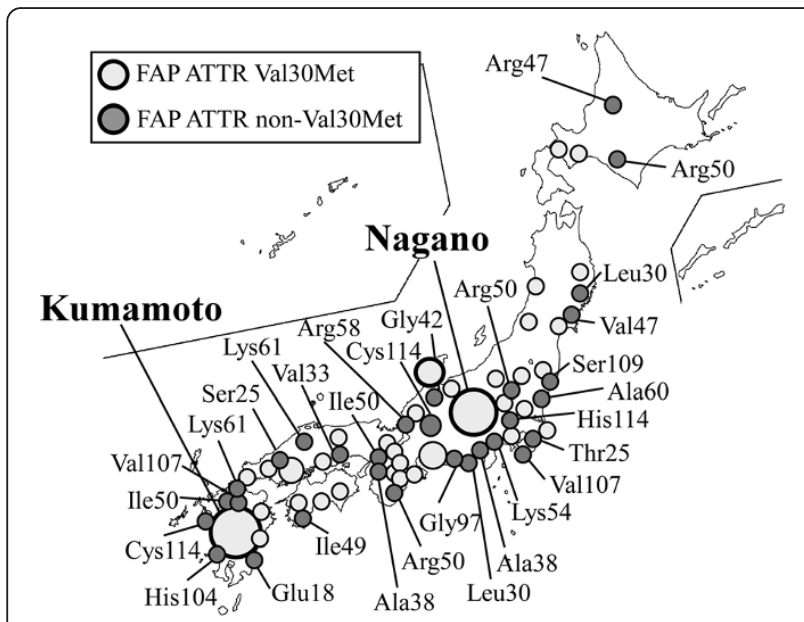

Figure 3 Distribution of hereditary TTR amyloidosis in Japan. addition to full-length WT TTR, truncated C-terminal WT TTR fragments starting at positions $46-52$ are usually detected in amyloid deposits obtained from SSA patients [32,35].

\section{Diagnosis}

Effective medical treatment of patients with TTR amyloidosis requires an accurate diagnosis based on various studies and techniques [42], such as histopathology, genetic testing, and mass spectrometry (Figure 4). Although diagnosis in the early stage of FAP is absolutely imperative for proper treatment, the diagnosis is sometimes delayed, especially in patients without a clear family history and typical clinical manifestations of FAP $[43,44]$.

Histopathological examinations play a critical role in obtaining direct evidence of amyloid deposits and determining the type of amyloid-causing protein [45]. Systemic amyloidosis including FAP is usually diagnosed on the basis of biopsies of several tissue sites, such as subcutaneous adipose tissue of the abdominal wall [46], GI tract $[47,48]$, and labial salivary gland [49], because biopsies of tissue sites with main clinical symptoms such as peripheral nerves, heart, and kidney are more invasive. Biopsy specimens are subjected to Congo red staining to detect amyloid deposits and are viewed with a microscope under polarized light. In patients with only a small amount of amyloid deposition, a confirmed diagnosis may require repeated biopsies. Most often, immunohistochemical determination of the chemical composition of amyloid 

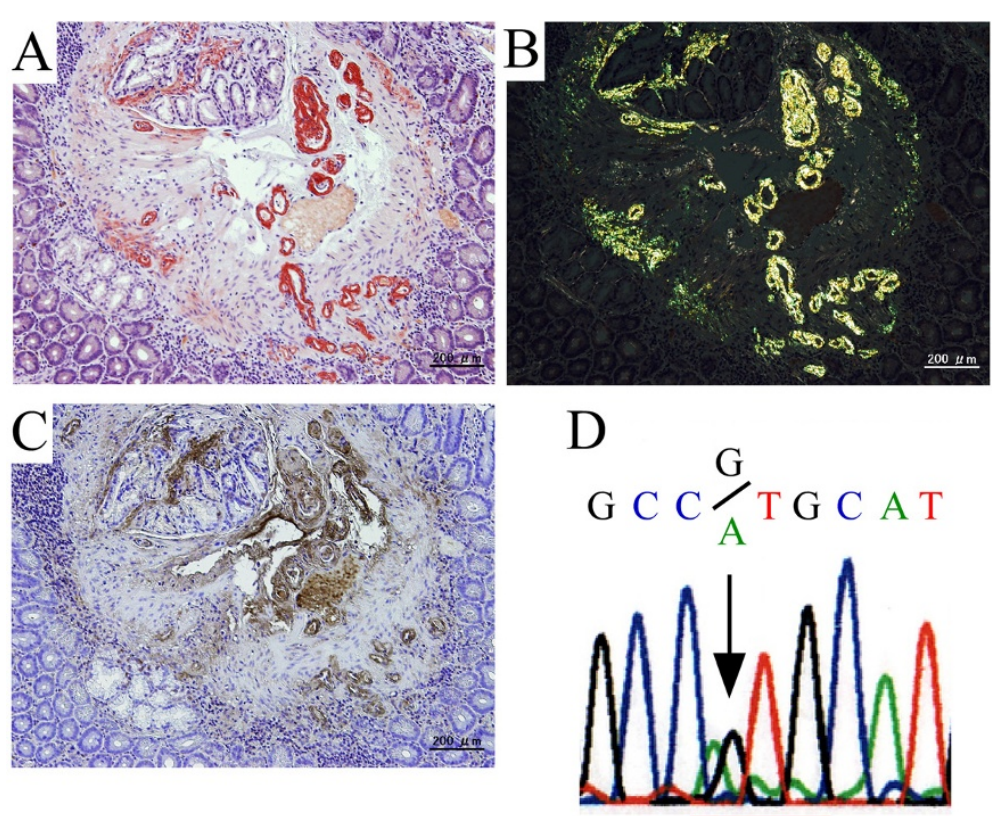

$\mathrm{E}$

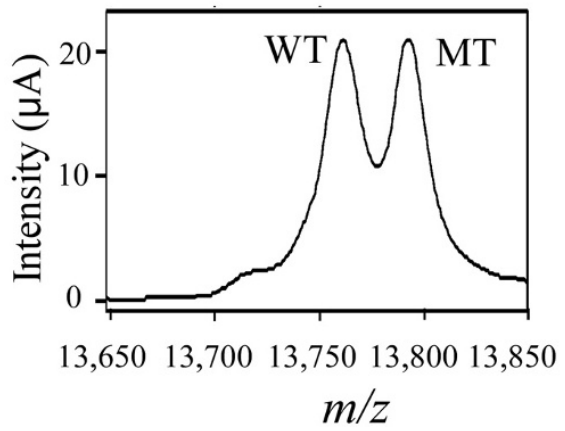

GTG (Val)

ATG (Met)

Figure 4 Diagnostic studies for FAP. (A-C) Histopathological images of a biopsy specimen of the duodenum obtained from an FAP ATTR Val30Met patient. (A) Congo red staining. (B) Polarized light. (C) Immunohistochemistry with an anti-TTR antibody. (D) Sequence analysis of the TTR gene. (E) SELDI-TOF MS analyses of serum TTR from an FAP ATTR Val30Met patient. The molecular weight of MT TTR is $32 \mathrm{~m} / \mathrm{z}$ higher than that of WT TTR.

is the first step in classifying the type of amyloid: a panel of antibodies recognizing different amyloid types is used to reveal the origin of deposited protein [50,51]. However, misdiagnoses have occurred in some cases, especially when immunohistochemical staining is performed in the absence of standardized antibodies and appropriate positive controls [52]. Extraction of amyloid fibril proteins from frozen and formalin-fixed tissues or from amyloidcontaining histopathological tissue sections followed by immunostaining or amino acid sequence analyses is another useful way to characterize amyloid deposits $[53,54]$, especially when immunohistochemical data are negative or inconclusive. A novel rapid test to determine the type of amyloidosis based on tandem mass spectrometric analysis, with specific sampling of clinical biopsy specimens by means of laser microdissection, was recently reported $[55,56]$. With this method, the authors successfully identified the amyloid proteins and classified the types of amyloidosis including TTR amyloidosis $[39,57]$. This method may be a useful clinical tool for aiding the accurate typing of amyloidosis.

To obtain accurate results for the TTR mutation in FAP patients or carriers of variant TTR genes, both genetic and proteomic methods should be applied to compensate for the disadvantages and possible pitfalls of each technique (Figure 4). Mass spectrometric analysis allows detection of variant TTRs in serum, because an amino acid substitution results in a change in the molecular weight of TTR circulating in the bloodstream [58-60]. We recently applied surface-enhanced laser desorption/ionization time-of-flight mass spectrometry (SELDI-TOF MS) to rapid detection of variant TTR in a patient's serum [61]. This technique allows the analysis of a variant form of TTR in a one-step procedure. 


\section{FAP treatments}

The sections that follow provide details of conventional and potential treatments of TTR amyloidosis (Figure 1).

\section{Liver transplantation}

With regard to treatment of FAP, liver transplantation (LT) has reportedly halted the progression of clinical manifestations [62,63]. Exchange of an FAP patient's diseased liver with a healthy liver causes MT TTR in the body to be replaced by WT TTR, except for cerebrospinal fluid and eyes, into which MT TTR is secreted from the choroid plexus and the retina, respectively, even after LT [64,65]. Since 1990, FAP patients have undergone LT as FAP treatment $[66,67]$. According to data in the FAP World Transplant Registry [66], approximately 120 orthotopic LTs are performed worldwide each year. LT reportedly prolonged the survival of FAP ATTR Val30Met patients who were carefully selected for the procedure $[68,69]$. The modified body mass index, disease duration, age, type of TTR mutation, and degree of cardiac involvement are thought to be important prognostic factors for the disease course after LT $[62,67,69]$. The survival rate of FAP ATTR non-Val30Met patients after LT was reportedly less than that of FAP ATTR Val30Met patients after LT $[66,70,71]$. LT could be less effective for the patients with ATTR non-Val30Met who have cardiomyopathy or leptomeningeal dominant symptoms.

Our criteria for performing LT for FAP patients were as follows: age younger than 60 years, duration of disease from onset $<5$ years, creatinine clearance $>70 \mathrm{ml} / \mathrm{min}$, modified body mass index $>500$, no cardiomegaly, and no gait disturbance [72]. The main causes of death in patients after orthotopic LTs involved cardiac problems (24\%), sepsis (23\%), and liver-related complications (14\%) [66,70,71]. Although clinical evaluations indicated that progression of other clinical symptoms such as peripheral neuropathy [73,74], GI symptoms [75], and renal involvement [72,76] usually stopped after LT in FAP ATTR Val30Met patients, other studies suggested that LT failed to prevent progression of cardiac amyloidosis in FAP ATTR Val30Met patients after LT [69,77], with this failure reportedly being due to continued formation of amyloid mainly derived from WT TTR secreted from the transplanted normal liver graft $[29,30,78]$. However, why WT TTR amyloid deposits, which are usually found in elderly people with SSA, occur in some tissue sites of FAP patients after LT remains to be clarified. It may be that older amyloid deposits formed by MT TTR before LT may act as a nidus, which is well known to enhance polymerization of proteins [79], and that additional WT TTR amyloid fibrils may form because of nucleation-dependent polymerization after LT, although TTR amyloid formation in vitro reportedly did not depend on nucleation [80].
Because of the shortage of livers for transplantation to patients with malignant or end-stage liver diseases, the method of using sequential LT with resected livers from FAP patients was developed [81]. Some patients who underwent sequential LT with livers from FAP patients reportedly started to evidence TTR amyloid deposits less than 10 years after the surgery [82-84]. However, we do not know whether all such second recipients will eventually have symptoms of FAP.

\section{Stabilizers of TTR tetramers: tafamidis and diflunisal}

The working hypothesis of amyloid formation established by a substantial number of studies led to the idea that stabilizing tetrameric TTR would be a promising method to prevent amyloid formation [85]. Tetrameric TTR itself is thought to be nonamyloidogenic, but dissociation of the tetramer into compact non-native monomers with low conformational stability can lead to amyloid fibril formation [86]. Baures et al. reported that, on the basis of in vitro experiments, various nonsteroidal anti-inflammatory drugs have potential for stabilizing tetrameric TTR [87]. These efforts thoroughly established this possibility of stabilization of the tetrameric form of TTR as a therapeutic strategy.

Two drugs-tafamidis, which is a novel TTR stabilizer, and diflunisal, which is a nonsteroidal anti-inflammatory drug developed in 1971 and can stabilize TTR tetramersare undergoing clinical development throughout the world. Tafamidis, a potent and selective stabilizer of tetrameric TTR, has been approved in Europe and Japan for treatment of adult FAP patients with early symptomatic polyneuropathy to delay neurological impairment $[88,89]$. In the clinical trial, patients treated with tafamidis had less neurological deterioration than patients who began tafamidis later; they had some preservation of function as measured by the Neuropathy Impairment Score-Lower Limb $[88,89]$. Recently, Berk et al. also reported that diflunisal reduced the rate of progression of neurological impairment and preserved quality of life [90]. Therapeutic effects of those TTR stabilizers on long-term outcomes, cardiac functions and ophthalmic symptom remain to be elucidated. Moreover, a number of structurally diverse small molecules that bind to TTR, increase its stability, and thereafter inhibit amyloid fibrillogenesis have been tested.

\section{Gene therapies to suppress TTR expression}

Knowledge gained by using LT as therapy for FAP suggested that inhibition of amyloidogenic TTR may prevent progression of the disease. Antisense methods and small interfering RNAs (siRNAs) are effective gene-silencing tools. The antisense oligonucleotides (ASO), which were recognized as a therapeutic tool in the 1970s, cause enzymatic degradation of mRNA. RNA interference, first discovered in Caenorhabditis elegans, is sequence- 
specific post-transcriptional gene silencing [91]. Specific gene expression has also been inhibited by RNA interference in mammalian cells by skipping the Dicer step [92]. These methods should be powerful tools for FAP gene therapy.

Early studies in this field aimed to selectively inhibit production of MT TTR. Different kinds of siRNA selectively silenced TTR gene expression both in vitro and in vivo [93]. Recently developed siRNA and ASO therapies, however, inhibit both MT TTR and WT TTR $[94,95]$, because WT TTR also contributes to the formation of amyloid in FAP, especially after LT. Benson et al. demonstrated that ASO suppressed TTR mRNA levels in the liver and in the choroid plexus of the brain [96,97]. Researchers completed a phase I study evaluating the safety and activity of ASO in healthy volunteers [95]. ASO reduced plasma TTR protein levels up to $80 \%$ without causing clinically significant adverse reactions. A phase II/ III study evaluating the efficacy of ASO in patients with FAP is ongoing in 2014. Also, a phase I clinical study with siRNA for FAP was completed [94], and a phase II/III study is ongoing in 2014.

\section{Retinal laser photocoagulation}

Even after LT, ocular complications have reportedly persisted and worsened, because RPE cells of the eye continued to synthesize MT TTR in FAP patients [64,98]. To suppress TTR synthesis and ocular symptoms, we have evaluated retinal laser photocoagulation. This operation, which is commonly used to treat many retinal diseases, damages the retinal pigment epithelium, the main location of synthesis of ATTR in ocular tissues. To date, we discovered that retinal laser photocoagulation clearly prevented progression of amyloid deposition in the vitreous and on the retinal surface in certain FAP patients, without causing any adverse effects [99]. Retinal laser photocoagulation may thus be a new procedure for mitigating ocular manifestations in FAP patients.

\section{4'-lodo-4'-deoxydoxorubicin, doxycycline, tauroursodeoxycholic acid, and cyclodextrin}

Other candidate therapeutic compounds, including 4'iodo-4' -deoxydoxorubicin (IDOX), doxycycline, tauroursodeoxycholic acid (TUDCA), and cyclodextrin (CyD), have also been studied.

Merlini et al. first reported IDOX as an agent that would bind to amyloid fibrils found in five different types of amyloidosis [100]. Sebastiao et al., in an in vitro study, noted the interaction of IDOX and ATTR Leu55Pro and reported the rapid dissociation of monoclinic ATTR Leu55Pro crystals soaked with IDOX [101].

Doxycycline influences many functions of mammalian cells such as proliferation, migration, apoptosis, and matrix remodeling [102]. Cardoso and colleagues investigated the effects of doxycycline treatment in vivo by using ATTR Val30Met transgenic mice [103,104].

TUDCA is a unique natural compound that is a potent antiapoptotic and antioxidant agent, as it reduces cytotoxicity in a number of neurodegenerative diseases. Macedo et al. studied the possible therapeutic application of TUDCA in FAP [105] and found that TUDCA treatment significantly decreased the amount of TTR toxic aggregates.

CyDs are cyclic oligosaccharides composed of 6-8 glucose units [106]. Because CyDs contain a central hydrophobic cavity, which can serve as an inclusion site for hydrophobic molecules, CyDs are now used as multifunctional drug carriers [107]. Jono et al. reported that 6-O- $\alpha$-(4-O- $\alpha$-D-glucuronyl)-D-glucosyl- $\beta$-CyD (GUG- $\beta$ CyD), a branched $\beta-C y D$ derivative, may inhibit TTR misfolding by stabilizing the conformation of TTR by means of interacting with hydrophobic amino acids, especially the Trp residue of TTR, which thereby suppresses TTR amyloid formation [108]. CyDs are safe and already widely used in many fields, especially pharmaceuticals, so GUG$\beta-C y D$ may become a curative drug for TTR amyloidosis.

\section{Gene conversion therapy}

As described above, LT was originally suggested as a treatment that would halt production of variant TTR in the liver. Most FAP symptoms do not progress after LT, when the MT TTR gene is replaced by the WT TTR gene in the liver. This finding led to the suggestion that gene therapy to correct the TTR gene mutation may ameliorate the clinical symptoms of FAP. Nakamura et al. demonstrated gene conversion by single-stranded oligonucleotides in rabbit eyes expressing rabbit WT TTR and in transgenic murine liver in which the intrinsic WT TTR gene was replaced by a TTR Val30Met gene [109].

\section{Immunotherapies}

Immunotherapies are also major candidates for TTR amyloidosis treatment. Gustavsson et al. used various antigenic mapping methods to find out whether major antigenic sites differed for normal TTR, ATTR, and in situ amyloid fibrils [110]. Their data suggested that antigenic sites on normal plasma TTR included the $A B$ and $\mathrm{CD}$ loops, with the associated amino acid sequences occurring on the outside of the TTR molecule. An antiserum against $\beta$-strand $\mathrm{H}$ (anti-TTR115-124), which establishes the dimer's monomer-to-monomer interaction areas, reacted with only ATTR in amyloid fibrils, not with normal TTR in plasma. These findings suggested an altered TTR configuration in amyloid fibrils compared with the TTR configuration in plasma. Thus, anti-TTR115-124, which seems to be amyloid specific, may be valuable as a probe and in antibody therapies.

An MT TTR Tyr78Phe that was designed to destabilize the native structure of TTR tetramer has exposed a cryptotope 
recognized by a monoclonal antibody that reacts only with amyloid fibrils or with highly amyloidogenic MTs that present the amyloid fold [111]. Terazaki et al. demonstrated that immunization with TTR Tyr78Phe effectively reduced TTR deposition and cleared amyloid deposits in an FAP rodent model transgenic for human TTR Val30Met with amyloid deposition in the GI tract [112]. This therapy may be applied to FAP ATTR Val30Met patients with amyloid deposition in tissues. In addition, this treatment may be useful for vaccination of healthy variant TTR gene carriers to prevent TTR amyloid deposition in tissues.

Serum amyloid P component (SAP) is a major component of amyloid deposits in all types of amyloidoses. Recently, Bodin, et al. investigated therapeutic effects of anti-human SAP antibodies on AA amyloid deposition using a human SAP transgenic mouse model [113]. The antibodies removed AA amyloid deposits in the mouse model. This antibody therapy might be applicable to FAP.

\section{Conclusions}

Although LT and TTR stabilizers became practical treatments for FAP, there remain many clinical issues we have to improve. Several clinical trials using other new methods are ongoing. These novel therapies may prove to prevent progression of FAP.

\begin{abstract}
Abbreviations
ASO: Antisense oligonucleotides; ATTR: Amyloidogenic TTR; FAP: Familial amyloidotic polyneuropathy; Gl: Gastrointestinal; GUG- $\beta-C y D$ : 6-O-a-(4-O-a-Dglucuronyl)-D-glucosyl- $\beta$-CyD; IDOX: 4'-iodo-4'-deoxydoxorubicin; LT: Liver transplantation; MT: Mutant; RPE: Retinal pigment epithelial; SELDI-TOF MS: Surface-enhanced laser desorption/ionization time-of-flight mass spectrometry; siRNAs: Small interfering RNAs; SSA: Senile systemic amyloidosis; TTR: Transthyretin; TUDCA: Tauroursodeoxycholic acid; WT: Wild-type.
\end{abstract}

\section{Competing interests}

The authors declare that they have no competing interests.

\section{Authors' contributions}

$\mathrm{MU}$ and YA drafted and revised the manuscript. Both authors read and approved the final manuscript.

\section{Acknowledgement}

We are indebted to Ms. Judith B. Gandy for editorial preparation of the manuscript. This research was supported by Grants-in-Aid for Science Research from the Ministry of Education, Culture, Sports, Science and Technology of Japan (numbers 17390254, 2196354).

\section{Author details}

${ }^{1}$ Department of Diagnostic Medicine, Graduate School of Medical Sciences, Kumamoto University, 1-1-1 Honjo, 860-0811 Kumamoto, Japan.

${ }^{2}$ Department of Neurology, Graduate School of Medical Sciences, Kumamoto University, 1-1-1 Honjo, 860-0811 Kumamoto, Japan.

Received: 9 June 2014 Accepted: 10 September 2014 Published: 13 September 2014

\section{References}

1. Ando $Y$, Nakamura M, Araki S: Transthyretin-related familial amyloidotic polyneuropathy. Arch Neurol 2005, 62:1057-1062.

2. Zeldenrust S, Benson MD: Familial and senile amyloidosis caused by transthyretin. In Protein Misfolding Diseases: Current and Emerging Principles and Therapies. Edited by Alvarado M, Kelly JW, Dobson CM. Hoboken, NJ: John Wiley \& Sons; 2010:795-815.

3. Planté-Bordeneuve V, Said G: Familial amyloid polyneuropathy. Lancet Neurol 2011, 10:1086-1097.

4. Ando $Y$, Ueda M: Diagnosis and therapeutic approaches to transthyretin amyloidosis. Curr Med Chem 2012, 19:2312-2323.

5. Ando Y: Liver transplantation and new therapeutic approaches for familial amyloidotic polyneuropathy (FAP). Med Mol Morphol 2005, 38:142-154.

6. Merlini G, Westermark P: The systemic amyloidoses: clearer understanding of the molecular mechanisms offers hope for more effective therapies. J Intern Med 2004, 255:159-178.

7. Benson MD: Amyloidosis in arthritis and allied conditions. In A Textbook of Rheumatology. Edited by Koopman WJ. Philadelphia: Lippincott Williams \& Wilkins; 2001:1866-1895.

8. Sipe JD, Cohen AS: Review: history of the amyloid fibril. J Struct Bio/ 2000, 130:88-98.

9. Sipe JD, Benson MD, Buxbaum JN, Ikeda S, Merlini G, Saraiva MJ, Westermark P, Nomenclature Committee of the International Society of Amyloidosis: Amyloid fibril protein nomenclature: 2012 recommendations from the Nomenclature Committee of the International Society of Amyloidosis. Amyloid 2012, 19:167-170.

10. Westermark P: Aspect of the history and nomenclature of amyloid and amyloidosis. In Amyloid and Related Disorders: Surgical Pathology and Clinical Correlations, Current Clinical Pathology. Edited by Picken MM, Dogan A, Herrera GA. New York: Springer Science + Business Media; 2012:3-8.

11. Benson MD: The hereditary amyloidoses. In Amyloid and Related Disorders: Surgical Pathology and Clinical Correlations, Current Clinical Pathology. Edited by Picken MM, Dogan A, Herrera GA. New York: Springer Science + Business Media; 2012:53-67.

12. Westermark P, Picken MM, Dogan A, Herrera GA: Localized amyloidoses and amyloidoses associated with aging outside the central nervous system. In Amyloid and Related Disorders: Surgical Pathology and Clinical Correlations, Current Clinical Pathology. New York: Springer Science + Business Media; 2012:81-103.

13. Richardson SJ: TTR synthesis during development and evolution: what the marsupials revealed. In Recent Advances in Transthyretin Evolution, Structure and Biological Functions. Edited by Richardson SJ, Cody V. Heidelberg: Springer; 2009:173-189.

14. Dickson PW, Schreiber G: High levels of messenger RNA for transthyretin (prealbumin) in human choroid plexus. Neurosci Lett 1986, 66:311-315.

15. Ong DE, Davis JT, O'Day WT, Bok D: Synthesis and secretion of retinol-binding protein and transthyretin by cultured retinal pigment epithelium. Biochemistry 1994, 33:1835-1842.

16. Westermark GT, Westermark P: Transthyretin and amyloid in the islets of Langerhans in type-2 diabetes. Exp Diabetes Res 2008, 2008:429274.

17. Zanotti G, Berni R: Plasma retinol-binding protein: structure and interactions with retinol, retinoids, and transthyretin. Vitam Horm 2004, 69:271-295.

18. Myron Johnson A, Merlini G, Sheldon J, Ichihara K: Clinical indications for plasma protein assays: transthyretin (prealbumin) in inflammation and malnutrition. Clin Chem Lab Med 2007, 45:419-426.

19. Westermark P, Bergström J, Solomon A, Murphy C, Sletten K: Transthyretinderived senile systemic amyloidosis: clinicopathologic and structural considerations. Amyloid 2003, 10:48-54.

20. Ueda M, Horibata Y, Shono M, Misumi Y, Oshima T, Su Y, Tasaki M, Shinriki S, Kawahara S, Jono H, Obayashi K, Ogawa H, Ando Y: Clinicopathological features of senile systemic amyloidosis: an ante- and post-mortem study. Mod Pathol 2011, 24:1533-1544.

21. Lai Z, Colón W, Kelly JW: The acid-mediated denaturation pathway of transthyretin yields a conformational intermediate that can selfassemble into amyloid. Biochemistry 1996, 35:6470-6482.

22. Araki S, Mawatari S, Ohta M, Nakajima A, Kuroiwa Y: Polyneurotic amyloidosis in a Japanese family. Arch Neurol 1968, 18:593-602.

23. Connors LH, Lim A, Prokaeva T, Roskens VA, Costello CE: Tabulation of human transthyretin (TTR) variants, 2003. Amyloid 2003, 10:160-184.

24. Mutations in Hereditary Amyloidosis. [http://amyloidosismutations.com/ attr.html]

25. Koike $H$, Misu K, Ikeda S, Ando $Y$, Nakazato $M$, Ando E, Yamamoto M, Hattori N, Sobue G, Study Group for Hereditary Neuropathy in Japan: Type I (transthyretin Met30) familial amyloid polyneuropathy in Japan: early- vs late-onset form. Arch Neurol 2002, 59:1771-1776. 
26. Koike H, Tanaka F, Hashimoto R, Tomita M, Kawagashira Y, lijima M, Fujitake J, Kawanami T, Kato T, Yamamoto M, Sobue G: Natural history of transthyretin Val30Met familial amyloid polyneuropathy: analysis of late-onset cases from non-endemic areas. J Neurol Neurosurg Psychiatry 2012, 83:152-158.

27. Hellman U, Suhr O: Regional differences and similarities of FAP in Sweden. Amyloid 2012, 19:53-54.

28. Bergström J, Gustavsson A, Hellman U, Sletten K, Murphy CL, Weiss DT, Solomon A, Olofsson BO, Westermark P: Amyloid deposits in transthyretinderived amyloidosis: cleaved transthyretin is associated with distinct amyloid morphology. J Pathol 2005, 206:224-232.

29. Ihse $E$, Suhr $O B$, Hellman U, Westermark P: Variation in amount of wildtype transthyretin in different fibril and tissue types in ATTR amyloidosis. J Mol Med (Berl) 2011, 89:171-180.

30. Oshima T, Kawahara S, Ueda M, Kawakami Y, Tanaka R, Okazaki T, Misumi Y, Obayashi K, Yamashita T, Ohya Y, Ihse E, Shinriki S, Tasaki M, Jono H, Asonuma $K$, Inomata $Y$, Westermark $P$, Ando $Y$ : Changes in pathological and biochemical findings of systemic tissue sites in familial amyloid polyneuropathy more than 10 years after liver transplantation. J Neurol Neurosurg Psychiatry 2014, 85:740-746.

31. Gustafsson $S$, Ihse $E$, Henein MY, Westermark $P$, Lindqvist $P$, Suhr OB: Amyloid fibril composition as a predictor of development of cardiomyopathy after liver transplantation for hereditary transthyretin amyloidosis. Transplantation 2012, 93:1017-1023.

32. Westermark $P$, Sletten $K$, Johansson B, Cornwell GG 3rd: Fibril in senile systemic amyloidosis is derived from normal transthyretin. Proc Natl Acad Sci U S A 1990, 87:2843-2845.

33. Falk RH: Cardiac amyloidosis: a treatable disease, often overlooked. Circulation 2011, 124:1079-1085.

34. Dubrey SW, Hawkins PN, Falk RH: Amyloid diseases of the heart: assessment, diagnosis, and referral. Heart 2011, 97:75-84.

35. Rapezzi C, Quarta CC, Riva L, Longhi S, Gallelli I, Lorenzini M, Ciliberti P, Biagini E, Salvi F, Branzi A: Transthyretin-related amyloidoses and the heart: a clinical overview. Nat Rev Cardiol 2010, 7:398-408.

36. Sueyoshi T, Ueda M, Sei A, Misumi Y, Oshima T, Yamashita T, Obayashi K, Shinriki S, Jono H, Shono M, Ando Y, Mizuta H: Spinal multifocal amyloidosis derived from wild-type transthyretin. Amyloid 2011, 18:165-168.

37. Lin JR, Wang $H$, Collins AB, Stone JR: Tongue necrosis and systemic vascular amyloidosis. Hum Pathol 2011, 42:734-737.

38. Tirzaman O, Wahner-Roedler DL, Malek RS, Sebo TJ, Li CY, Kyle RA: Primary localized amyloidosis of the urinary bladder: a case series of 31 patients. Mayo Clin Proc 2000, 75:1264-1268.

39. Roden AC, Aubry MC, Zhang K, Brady JO, Levin D, Dogan A, Yi ES: Nodular senile pulmonary amyloidosis: a unique case confirmed by immunohistochemistry, mass spectrometry, and genetic study. Hum Pathol 2010, 41:1040-1045.

40. Sueyoshi T, Ueda M, Jono H, Irie H, Sei A, Ide J, Ando Y, Mizuta H: Wild-type transthyretin-derived amyloidosis in various ligaments and tendons. Hum Pathol 2011, 42:1259-1264.

41. Sekijima Y, Uchiyama S, Tojo K, Sano K, Shimizu Y, Imaeda T, Hoshii Y, Kato $H$, Ikeda S: High prevalence of wild-type transthyretin deposition in patients with idiopathic carpal tunnel syndrome: a common cause of carpal tunnel syndrome in the elderly. Hum Pathol 2011, 42:1785-1791.

42. Ando Y, Ueda M: Proteomics for transthyretin (TTR) related amyloidosis Curr Proteomics 2011, 8:237-246.

43. Koike H, Hashimoto R, Tomita M, Kawagashira Y, lijima M, Tanaka F, Sobue G: Diagnosis of sporadic transthyretin Val30Met familial amyloid polyneuropathy: a practical analysis. Amyloid 2011, 18:53-62

44. Planté-Bordeneuve V, Ferreira A, Lalu T, Zaros C, Lacroix C, Adams D, Said G: Diagnostic pitfalls in sporadic transthyretin familial amyloid polyneuropathy (TTR-FAP). Neurology 2007, 69:693-698.

45. Grateau G, Stankovic: Diagnosis and classification. In myloidosis: Diagnosis and Treatment. Edited by Gertz M, Rajkumar SV. New York: Springer Science + Business Media; 2010:33-48.

46. Westermark P: Subcutaneous adipose tissue biopsy for amyloid protein studies. Methods Mol Biol 2012, 849:363-371.

47. Kyle RA, Spencer RJ, Dahlin DC: Value of rectal biopsy in the diagnosis of primary systemic amyloidosis. Am J Med Sci 1966, 251:501-506.

48. Röcken C, Sletten K: Amyloid in surgical pathology. Virchows Arch 2003, $443: 3-16$
49. Lechapt-Zalcman E, Authier FJ, Creange A, Voisin MC, Gherardi RK: Labial salivary gland biopsy for diagnosis of amyloid polyneuropathy. Muscle Nerve 1999, 22:105-107.

50. Gertz MA: The classification and typing of amyloid deposits. Am J Clin Pathol 2004, 121:787-789.

51. Murphy CL, Eulitz M, Hrncic R, Sletten K, Westermark P, Williams T, Macy SD, Wooliver C, Wall J, Weiss DT, Solomon A: Chemical typing of amyloid protein contained in formalin-fixed paraffin-embedded biopsy specimens. Am J Clin Pathol 2001, 116:135-142.

52. Linke RP, Oos R, Wiegel NM, Nathrath WB: Classification of amyloidosis: misdiagnosing by way of incomplete immunohistochemistry and how to prevent it. Acta Histochem 2006, 108:197-208,

53. Kaplan B, Shtrasburg S, Pras M: Micropurification techniques in the analysis of amyloid proteins. J Clin Pathol 2003, 56:86-90.

54. Kaplan B, Martin BM, Livneh A, Pras M, Gallo GR: Biochemical subtyping of amyloid in formalin-fixed tissue samples confirms and supplements immunohistologic data. Am J Clin Pathol 2004, 121:794-800.

55. Vrana JA, Gamez JD, Madden BJ, Theis JD, Bergen HR 3rd, Dogan A: Classification of amyloidosis by laser microdissection and mass spectrometry-based proteomic analysis in clinical biopsy specimens. Blood 2009, 114:4957-4959.

56. Dogan A, Picken MM, Dogan A, Herrera GA: Classification of amyloidosis by mass spectrometry-based proteomics. In Amyloid and Related Disorders: Surgical Pathology and Clinical Correlations, Current Clinical Pathology. New York: Springer Science + Business Media; 2012:261-272.

57. Klein CJ, Vrana JA, Theis JD, Dyck PJ, Dyck PJ, Spinner RJ, Mauermann ML, Bergen HR 3rd, Zeldenrust SR, Dogan A: Mass spectrometric-based proteomic analysis of amyloid neuropathy type in nerve tissue. Arch Neurol 2011, 68:195-199.

58. Ando Y, Ohlsson Pl, Suhr O, Nyhlin N, Yamashita T, Holmgren G, Danielsson A, Sandgren O, Uchino M, Ando M: A new simple and rapid screening method for variant transthyretin-related amyloidosis. Biochem Biophys Res Commun 1996, 228:480-483.

59. Yamashita T, Ando Y, Bernt Suhr O, Nakamura M, Sakashita N, Ohlsson PI, Terazaki H, Obayashi K, Uchino M, Ando M: A new diagnostic procedure to detect unknown transthyretin (TTR) mutations in familial amyloidotic polyneuropathy (FAP). J Neurol Sci 2000, 173:154-159.

60. Bergquist J, Andersen O, Westman A: Rapid method to characterize mutations in transthyretin in cerebrospinal fluid from familial amyloidotic polyneuropathy patients by use of matrix-assisted laser desorption/ionization time-of-flight mass spectrometry. Clin Chem 2000, 46:1293-1300

61. Ueda M, Misumi Y, Mizuguchi M, Nakamura M, Yamashita T, Sekijima $Y$, Ota K, Shinriki S, Jono H, Ikeda S, Suhr OB, Ando Y: SELDI-TOF mass spectrometry evaluation of variant transthyretins for diagnosis and pathogenesis of familial amyloidotic polyneuropathy. Clin Chem 2009, 55:1223-1227.

62. Ericzon $\mathrm{G}$, Lundgren $\mathrm{E}$, Suhr $\mathrm{O}$ : Liver transplantation for transthyretin amyloidosis. In Recent Advances in Transthyretin Evolution, Structure and Biological Functions. Edited by Richardson SJ, Cody V. Heidelberg: Springer; 2009:239-260

63. Stangou AJ, Hawkins PN: Liver transplantation in transthyretin-related familial amyloid polyneuropathy. Curr Opin Neurol 2004, 17:615-620.

64. Ando $Y$, Terazaki $H$, Nakamura M, Ando E, Haraoka K, Yamashita T, Ueda M, Okabe H, Sasaki Y, Tanihara H, Uchino M, Inomata Y: A different amyloid formation mechanism: de novo oculoleptomeningeal amyloid deposits after liver transplantation. Transplantation 2004, 77:345-349.

65. Said G, Planté-Bordeneuve V: Familial amyloid polyneuropathy: a clinicopathologic study. J Neurol Sci 2009, 284:149-154.

66. Familial Amyloidotic Polyneuropathy World Transplant Registry. [http://www.fapwtr.org/]

67. Suhr $O B$, Friman S, Ericzon BG: Early liver transplantation improves familial amyloidotic polyneuropathy patients' survival. Amyloid 2005, 12:233-238.

68. Yamashita T, Ando Y, Okamoto S, Misumi Y, Hirahara T, Ueda M, Obayashi K, Nakamura M, Jono $H$, Shono M, Asonuma K, Inomata $Y$, Uchino M: Long-term survival after liver transplantation in patients with familial amyloid polyneuropathy. Neurology 2012, 78:637-643.

69. Yamamoto S, Wilczek HE, Nowak G, Larsson M, Oksanen A, Iwata T, Gjertsen H, Söderdahl G, Wikström L, Ando Y, Suhr OB, Ericzon BG: Liver transplantation for familial amyloidotic polyneuropathy (FAP): a single-center experience over 16 years. Am J Transplant 2007, 7:2597-2604 
70. Wilczek H, Larsson M, Ericzon B: Long-term data from the Familial Amyloidotic Polyneuropathy World Transplant Registry (FAPWTR). Amyloid 2011, 18:188-190.

71. Benson MD: Liver transplantation and transthyretin amyloidosis. Muscle Nerve 2013, 47:157-162.

72. Ohya Y, Okamoto S, Tasaki M, Ueda M, Jono H, Obayashi K, Takeda K, Okajima $\mathrm{H}$, Asonuma K, Hara R, Tanihara H, Ando Y, Inomata Y: Manifestations of transthyretin-related familial amyloidotic polyneuropathy: long-term follow-up of Japanese patients after liver transplantation. Surg Today 2011, 41:1211-1218.

73. Adams D, Samuel D, Goulon-Goeau C, Nakazato M, Costa PM, Feray C, Planté V, Ducot B, Ichai P, Lacroix C, Metral S, Bismuth H, Said G: The course and prognostic factors of familial amyloid polyneuropathy after liver transplantation. Brain 2000, 123:1495-1504

74. de Carvalho M, Conceição I, Bentes C, Luís ML: Long-term quantitative evaluation of liver transplantation in familial amyloid polyneuropathy (Portuguese V30M). Amyloid 2002, 9:126-133.

75. Suhr OB, Anan I, Ahlström KR, Rydh A: Gastric emptying before and after liver transplantation for familial amyloidotic polyneuropathy, Portuguese type (Val30Met). Amyloid 2003, 10:121-126.

76. Nowak G, Suhr OB, Wikström L, Wilczek H, Ericzon BG: The long-term impact of liver transplantation on kidney function in familial amyloidotic polyneuropathy patients. Transp/ Int 2005, 18:111-115.

77. Hörnsten R, Wiklund U, Olofsson BO, Jensen SM, Suhr OB: Liver transplantation does not prevent the development of life-threatening arrhythmia in familial amyloidotic polyneuropathy, Portuguese-type (ATTR Val30Met) patients. Transplantation 2004, 78:112-116.

78. Liepnieks JJ, Benson MD: Progression of cardiac amyloid deposition in hereditary transthyretin amyloidosis patients after liver transplantation. Amyloid 2007, 14:277-282.

79. Morris AM, Watzky MA, Finke RG: Protein aggregation kinetics, mechanism, and curve-fitting: a review of the literature. Biochim Biophys Acta 2009, 1794:375-397.

80. Hurshman AR, White JT, Powers ET, Kelly JW: Transthyretin aggregation under partially denaturing conditions is a downhill polymerization. Biochemistry 2004, 43:7365-7381.

81. Monteiro E, Perdigoto R, Furtado AL: Liver transplantation for familial amyloid polyneuropathy. Hepatogastroenterology 1998, 45:1375-1380.

82. Stangou AJ, Heaton ND, Hawkins PN: Transmission of systemic transthyretin amyloidosis by means of domino liver transplantation. N Engl J Med 2005, 352:2356.

83. Goto T, Yamashita T, Ueda M, Ohshima S, Yoneyama K, Nakamura M, Nanjo H, Asonuma K, Inomata Y, Watanabe S, Uchino M, Tanaka K, Ando Y: latrogenic amyloid neuropathy in a Japanese patient after sequential liver transplantation. Am J Transplant 2006, 6:2512-2515.

84. Takei Y, Gono T, Yazaki M, Ikeda S, Ikegami T, Hashikura Y, Miyagawa S, Hoshii Y: Transthyretin-derived amyloid deposition on the gastric mucosa in domino recipients of familial amyloid polyneuropathy liver. Liver Transpl 2007, 13:215-218.

85. Johnson SM, Connelly S, Fearns C, Powers ET, Kelly JW: The transthyretin amyloidoses: from delineating the molecular mechanism of aggregation linked to pathology to a regulatory-agency-approved drug. J Mol Biol 2012, 421:185-203.

86. Quintas A, Saraiva MJ, Brito RM: The tetrameric protein transthyretin dissociates to a non-native monomer in solution. A novel model for amyloidogenesis. J Biol Chem 1999, 274:32943-32949.

87. Baures PW, Oza VB, Peterson SA, Kelly JW: Synthesis and evaluation of inhibitors of transthyretin amyloid formation based on the non-steroidal anti-inflammatory drug, flufenamic acid. Bioorg Med Chem 1999, 7:1339-1347.

88. Coelho T, Maia LF, Martins da Silva A, Waddington Cruz M, PlantéBordeneuve V, Lozeron P, Suhr OB, Campistol JM, Conceição IM, Schmidt HH, Trigo P, Kelly JW, Labaudinière R, Chan J, Packman J, Wilson A, Grogan DR: Tafamidis for transthyretin familial amyloid polyneuropathy: a randomized, controlled trial. Neurology 2012, 79:785-792.

89. Coelho T, Maia LF, da Silva AM, Cruz MW, Planté-Bordeneuve V, Suhr OB, Conceiçao I, Schmidt HH, Trigo P, Kelly JW, Labaudinière R, Chan J, Packman J, Grogan DR: Long-term effects of tafamidis for the treatment of transthyretin familial amyloid polyneuropathy. J Neurol 2013, 260:2802-2814.

90. Berk JL, Suhr OB, Obici L, Sekijima Y, Zeldenrust SR, Yamashita T, Heneghan MA, Gorevic PD, Litchy WJ, Wiesman JF, Nordh E, Corato M, Lozza A,
Cortese A, Robinson-Papp J, Colton T, Rybin DV, Bisbee AB, Ando Y, Ikeda S, Seldin DC, Merlini G, Skinner M, Kelly JW, Dyck PJ, Diflunisal Trial Consortium: Repurposing diflunisal for familial amyloid polyneuropathy: a randomized clinical trial. JAMA 2013, 310:2658-2667.

91. Fire A, Xu S, Montgomery MK, Kostas SA, Driver SE, Mello CC: Potent and specific genetic interference by double-stranded RNA in Caenorhabditis elegans. Nature 1998, 391:806-811.

92. Elbashir SM, Harborth J, Lendeckel W, Yalcin A, Weber K, Tuschl T: Duplexes of 21-nucleotide RNAs mediate RNA interference in cultured mammalian cells. Nature 2001, 411:494-498.

93. Kurosawa T, Igarashi S, Nishizawa M, Onodera O: Selective silencing of a mutant transthyretin allele by small interfering RNAs. Biochem Biophys Res Commun 2005, 337:1012-1018.

94. Coelho T, Adams D, Silva A, Lozeron P, Hawkins PN, Mant T, Perez J, Chiesa J, Warrington S, Tranter E, Munisamy M, Falzone R, Harrop J, Cehelsky J, Bettencourt BR, Geissler M, Butler JS, Sehgal A, Meyers RE, Chen Q, Borland T, Hutabarat RM, Clausen VA, Alvarez R, Fitzgerald K, Gamba-Vitalo C, Nochur SV, Vaishnaw AK, Sah DW, Gollob JA, et al: Safety and efficacy of RNAi therapy for transthyretin amyloidosis. N Engl J Med 2013, 369:819-829.

95. Ackermann EJ, Guo S, Booten S, Alvarado L, Benson M, Hughes S, Monia BP: Clinical development of an antisense therapy for the treatment of transthyretin-associated polyneuropathy. Amyloid 2012, 19:43-44.

96. Benson MD, Kluve-Beckerman B, Zeldenrust SR: Targeted suppression of an amyloidogenic transthyretin with antisense oligonucleotides. Muscle Nerve 2006, 33:609-618.

97. Benson MD, Smith RA, Hung G, Kluve-Beckerman B, Showalter AD, Sloop KW, Monia BP: Suppression of choroid plexus transthyretin levels by antisense oligonucleotide treatment. Amyloid 2010, 17:43-49.

98. Haraoka K, Ando Y, Ando E, Sun X, Nakamura M, Terazaki H, Misumi S, Tanoue $Y$, Tajiiri T, Shoji S, Ishizaki T, Okabe H, Tanihara H: Presence of variant transthyretin in aqueous humor of a patient with familial amyloidotic polyneuropathy after liver transplantation. Amyloid 2002, 9:247-251

99. Kawaji $T$, Ando $Y$, Hara $R$, Tanihara H: Novel therapy for transthyretin-related ocular amyloidosis: a pilot study of retinal laser photocoagulation. Ophthalmology 2010, 117:552-555.

100. Merlini G, Ascari E, Amboldi N, Bellotti V, Arbustini E, Perfetti V, Ferrari M, Zorzoli I, Marinone MG, Garini P, Diegoli M, Trizio D, Ballinari D: Interaction of the anthracycline 4'-iodo-4'-deoxydoxorubicin with amyloid fibrils: inhibition of amyloidogenesis. Proc Natl Acad Sci U S A 1995, 92:2959-2963.

101. Sebastiao MP, Merlini G, Saraiva MJ, Damas AM: The molecular interaction of 4'-iodo-4'-deoxydoxorubicin with Leu-55Pro transthyretin 'amyloid-like' oligomer leading to disaggregation. Biochem J 2000, 351:273-279.

102. Bendeck MP, Conte M, Zhang M, Nili N, Strauss BH, Farwell SM: Doxycycline modulates smooth muscle cell growth, migration, and matrix remodeling after arterial injury. Am J Pathol 2002, 160:1089-1095.

103. Cardoso I, Merlini G, Saraiva MJ: 4'-lodo-4'-deoxydoxorubicin and tetracyclines disrupt transthyretin amyloid fibrils in vitro producing noncytotoxic species. Screening for TTR fibril disrupters. FASEB J 2003 , 17:803-809.

104. Cardoso I, Saraiva MJ: Doxycycline disrupts transthyretin amyloid: evidence from studies in a FAP transgenic mice model. FASEB J 2006, 20:234-239.

105. Macedo B, Batista AR, Ferreira N, Almeida MR, Saraiva MJ: Anti-apoptotic treatment reduces transthyretin deposition in a transgenic mouse model of familial amyloidotic polyneuropathy. Biochim Biophys Acta 2008, 1782:517-522.

106. Uekama K, Hirayama F, Irie T: Cyclodextrin drug carrier systems. Chem Rev 1998, 98:2045-2076.

107. Davis ME, Brewster ME: Cyclodextrin-based pharmaceutics: past, present and future. Nat Rev Drug Discov 2004, 3:1023-1035.

108. Jono H, Anno T, Motoyama K, Misumi Y, Tasaki M, Oshima T, Mori Y, Mizuguchi M, Ueda M, Shono M, Obayashi K, Arima H, Ando Y: Cyclodextrin, a novel therapeutic tool for suppressing amyloidogenic transthyretin misfolding in transthyretin-related amyloidosis. Biochem J 2011, 437:35-42

109. Nakamura M, Ando $Y$, Nagahara S, Sano A, Ochiya T, Maeda S, Kawaji T, Ogawa M, Hirata A, Terazaki H, Haraoka K, Tanihara H, Ueda M, Uchino M, Yamamura $\mathrm{K}$ : Targeted conversion of the transthyretin gene in vitro and in vivo. Gene Ther 2004, 11:838-846.

110. Gustavsson A, Engström U, Westermark P: Mechanisms of transthyretin amyloidogenesis. Antigenic mapping of transthyretin purified from 
plasma and amyloid fibrils and within in situ tissue localizations. Am J Pathol 1994, 144:1301-1311.

111. Redondo C, Damas AM, Olofsson A, Lundgren E, Saraiva MJ: Search for intermediate structures in transthyretin fibrillogenesis: soluble tetrameric Tyr78Phe TRR expresses a specific epitope present only in amyloid fibrils. J Mol Biol 2000, 304:461-470.

112. Terazaki H, Ando Y, Fernandes R, Yamamura K, Maeda S, Saraiva MJ: Immunization in familial amyloidotic polyneuropathy: counteracting deposition by immunization with a Y78F TTR mutant. Lab Invest 2006, 86:23-31.

113. Bodin K, Ellmerich S, Kahan MC, Tennent GA, Loesch A, Gilbertson JA, Hutchinson WL, Mangione PP, Gallimore JR, Millar DJ, Minogue S, Dhillon AP, Taylor GW, Bradwell AR, Petrie A, Gillmore JD, Bellotti V, Botto M, Hawkins PN, Pepys MB: Antibodies to human serum amyloid P component eliminate visceral amyloid deposits. Nature 2010, 468:93-97.

doi:10.1186/2047-9158-3-19

Cite this article as: Ueda and Ando: Recent advances in transthyretin amyloidosis therapy. Translational Neurodegeneration 2014 3:19.

\section{Submit your next manuscript to BioMed Central and take full advantage of:}

- Convenient online submission

- Thorough peer review

- No space constraints or color figure charges

- Immediate publication on acceptance

- Inclusion in PubMed, CAS, Scopus and Google Scholar

- Research which is freely available for redistribution 